\title{
The Cubrix, an Integral Framework for Managing Performance Improvement and Organisational Development
}

\author{
Marcel van Marrewijk \\ Research to Improve, Trusting Companies International and Virtu et Fortuna, Vlaardingen, Netherland \\ E-mail:marcel@vanmarrewijk.nl
}

Received October 26, 2009; revised November 23, 2009; accepted December 25, 2009

\begin{abstract}
Marcel van Marrewijk, academic director of Research to Improve, has developed an integral, multi-level, multi-disciplinary and multi-stakeholder management framework, based on a phase-wise development approach as described by Clare Graves' Levels of Existence Theory, Ken Wilber's Four Quadrant Theory and the author's Global Excellence Model. This conceptual framework is coined, the Cubrix.

This paper shortly introduces the three original concepts and shows how these models have been merged into the Cubrix. In part two the author demonstrates how Research to Improve designed various surveys, scans, monitors and assessments, all based on this framework. Furthermore, the Cubrix has also been supportive in designing the Performance Improvement Cycle and offer input for developing roadmaps for transitions in organization development.
\end{abstract}

Keywords: Value Systems, Spiral Dynamics, GEM, Cubrix, Transition Matrix, Research Framework, Sustainable Performance, Organisation Development, Transformations, High Performance Organisations

\section{Introduction}

2001, Van Marrewijk, in collaboration with Erasmus University Rotterdam, launched an international research project in response to an EC-assignment to develop an integral model for Corporate Social Responsibility, CSR. More than two years later, a consortium of experts delivered the European Corporate Sustainability Framework (ECSF) to the European Commission. It was a new generation management framework, demonstrating company responsible ways of doing business while achieving higher performance levels as sustainable operating organizations, carefully aligning their particular development level(s) with their major challenges [1-3].

The ECSF-research project succeeded in identifying various ways of interpreting Corporate Sustainability and Responsibility (CS-R) and aligning specific ambitions with respect to CS-R and with adequate ways of implementing it. The generic definition of CS-R is the corporate inclusion of social and environmental concerns into business operations and in interactions with stakeholders. Van Marrewijk [4] concluded that corporate responsibility (CR) expresses the corporation's willingness to be accountable for the impact of their doing to stakeholders
(Communion) and relates to phenomena such as transparency, stakeholder dialogue and sustainability reporting. On the other hand, corporate sustainability (CS) is manifested as the organization's capacity (Agency) to improve value creation with respect to the triple bottom line (people, planet \& profit), due to for instance environmental friendly production systems, waste reduction policies, recycling, human potential development programs, fair trade, green energy and many more ways to improve multiple performances.

The ECSF framework hosts traditional ways of doing business, such as compliance-driven and profit-driven approaches. It also includes business approaches that have emerged only recently, such as more care-driven and synergy-driven ways of organizational behaviour [5]. Each respective approach characterizes a specific development level, transcending and including the former ones and each supported by particular value systems and management paradigms, demonstrated in coherent sets of institutional structures [6]. Business phenomena such as CS-R can thus be interpreted by each of these systems, taking different manifestations per development level $[4,5]$ :

1) Compliance-driven: CS-R at this level consists of 
providing welfare to society, within the limits of regulations from the rightful authorities. In addition, organizations might respond to charity and stewardship considerations. The motivation for CS-R is that CS-R is perceived as a duty and obligation, or correct behavior.

2) Profit-driven: CS-R at this level consists of the integration of social, ethical and ecological aspects into business operations and decision-making, provided it contributes to the financial bottom line. The motivation for CS-R is a business case: CS-R is promoted if profitable, for example because of an improved reputation in various markets (customers/employees/shareholders).

3) Care-driven: CS-R consists of balancing economic, social and ecological concerns, which are all three important in themselves. CS-R initiatives go beyond legal compliance and beyond profit considerations. The motivation for CS is that human potential, social responsibility and care for the planet are as such important.

4) Synergy-driven: CS-R consists of a search for well-balanced, functional solutions creating value in the economic, social and ecological realms of corporate performance, in a synergistic, win-together approach with all relevant stakeholders. The motivation for CS is that sustainability is crucial as it is recognized as being the inevitable direction progress takes.

5) Holistic-driven: CS-R is fully integrated and embedded in every aspect of the organization, aimed at contributing to the quality and continuation of life of every being and entity, now and in the future. The motivation for CS is that sustainability is the only alternative since all beings and phenomena are mutually interdependent. Each person or organization therefore has a universal responsibility towards all other beings.

Too often confronted with pretentious and manipulative CS-R communication (green washing), Van Marrewijk concluded that building cultures of trust within organisations was the first practical and effective step in achieving authentic corporate sustainability and responsibility. He became director Great Place to Work ${ }^{\circledR}$ Institute Netherlands, engaged primarily with transforming workplaces through research, and 'naming and faming' best practices in various award activities [2].

In 2005 he was member of an EC-research project, coordinated by Esade Business School, analysing Great Place to Work ${ }^{\circledR}$ data gathered from over 1,000 European companies. The data showed a pattern in which the best Scandinavian workplaces outperformed the ones in the Mediterranean countries. The GPTW ${ }^{\circledR}$ model is not able to explain such patterns. Once more, Van Marrewijk turned to Spiral Dynamics and Wilber's Four Quadrant (SDI) to develop a sequence of macro-economic systems, running from self sufficiency, pre-capitalist and various classical economies, capitalist (Anglo-Saxon) and socialist market (Rhineland) economies and the emerging interdependent economy [7]. Again, each economic sys- tem transcends and includes the less complex ones. Therefore the socialist market economy, predominantly present in northern continental Europe, show plenty reminiscents of former systems, such as excessive rewarding practices for CEO's.

From 2000 on, Van Marrewijk remained board member of the Dutch branch of the European Federation for Quality Management, the EFQM. The ECSF consortium of international researchers ${ }^{2}$ was mainly drawn from an international network of quality experts. Its outcome, the ECSF framework was placed within the quality management tradition, as it regarded complex interpretations of CS-R as integral part of business improvement and organizational excellence.

Despite its elegance in framing management attention areas, the EFQM model, officially named the European Model for Business Excellence, is 'as flat as a pancake', in other words, it lacks depth to generate adequate understanding of complex organisations. In order to align the EFQM model within the ECSF framework, Van [8] adapted the EFQM model, by introducing depth and providing various contexts to business excellence, thus creating a multi-level, a multi-disciplinary and multi-stakeholder Global Excellence Model (GEM). In this paper, while discussing the GEM, the author will further elaborate on this topic.

Van Marrewijk remained enthusiastic with his multilevel approach applied to corporate sustainability and business excellence. He developed it into an even more sophisticated framework, which he coined the 'Cubrix', a cubical framework based on three dimensions: development levels (Spiral Dynamics Integral), management attention areas or disciplines, and stakeholders (both Global Excellence Model), the topic of this paper.

In practice, van Marrewijk remained preoccupied with the introduction of the rather one-dimensional Great Place to Work Concept in the Netherlands. In providing feedback to companies on the quality of their workplaces, van Marrewijk noticed that the human resource management approach is often dominant, jeopardizing the transformation towards more promising approaches. Again, the 'flat pancake' syndrome was bothering corporate development as many people managers seemed to be 'arrested' in their constrained and limited set of policies and practices. He felt the time was ready to apply new concepts to corporate research, aligning it with learning and performance improvement. He left Great Place to Work Institute Nederland to his successors and founded a new research institute, Research to Improve and started anew.

This paper elaborates on the content and structure of the Cubrix and demonstrates its use in the development of new research tools. It also deals with some derivatives from the Cubrix such as the Performance Improvement Cycle and the way to design roadmaps for organisation development and performance improvement. 


\subsection{Structure of This Paper}

Paragraph two starts with a short introduction of Spiral Dynamics Integral, as developed by Clare W. Graves, his successors Don Beck and Chris Cowan [9], and Ken Wilber [9]. Also the second fundament underlying the Cubrix, the Global Excellence Model, will be introduced. Paragraph three describes the Cubrix. Paragraph four deals with research tools based on the Cubrix and paragraph five introduces derivatives from the Cubrix, with impact on change management and the design of a roadmap for organization development and performance improvement.

\section{Supportive Structures of the Cubrix: Contexts}

\subsection{The Gravesian Approach to Development}

Clare W. Graves, professor psychology at Union College, New York, teaching sections on psychological approaches of Freud and Jung, Watson and Skinner, Maslow and others, was confronted by his students: "OK, Dr. Graves, which one is right?" Graves recognized that all the theories had elements of truth, as well as holes. It led him on a thirty-year quest to better understand the emerging nature of psychologically healthy human beings. It placed him among scientists that try to structure evolutionary aspects of development. See Table 1.

In the 1950s throughout the early 1970 s, professor Graves performed extensive empirical research on value systems. He coined his model: the Emergent, Cyclical, Double-Helix Model of Adult BioPsychoSocial Systems Development or, for short, Emerging Cyclical Level of Existence Theory (ECLET). As an introduction to his framework each qualification will be briefly summarized.

\subsubsection{Emergent}

With respect to 'emergent', Graves concluded that mankind has gradually developed eight levels of existence or core value systems, so far. A value system is a way of conceptualizing reality and encompasses a consistent set of values, beliefs and corresponding behaviour and can be found in individual persons, as well as in companies and societies [9]. With these statements, Graves confronted Maslow's 'Hierarchy of Needs'. He agreed to the ranking of the needs, but the image of a pyramid cannot express the emerging capacities of human beings in meeting higher levels of complexity, thus creating different manifestations of personal and collective self-actualisation. Graves' successors, Beck \& Cowan, created the image of a spiral, emphasising the open ended and ever expanding nature of their approach.

Human development is an emergent, oscillating proc-
Table 1. Evolutionary aspects.

\begin{tabular}{|c|c|c|}
\hline Line & Life's question & Typical researcher \\
\hline Aesthetic & What is attractive to me? & Housen \\
\hline Cognitive & What am I aware of? & Piaget, Kean \\
\hline Emotional & How do I feel about this? & Goleman \\
\hline Interpersonal & How should we interact? & Selman, Perry \\
\hline Kinesthetic & $\begin{array}{l}\text { How should I physically do } \\
\text { this? }\end{array}$ & Gardner \\
\hline Moral & What should I do? & Kohlberg \\
\hline Needs & What do I need? & Maslow \\
\hline Self & Who am I? & Loevinger \\
\hline Spiritual & What is of ultimate concern? & Fowler \\
\hline Values & What is significant to me? & $\begin{array}{l}\text { Graves, } \\
\text { Dynamics }\end{array}$ \\
\hline
\end{tabular}

ess that subordinates older, less complex ways of thinking/being to newer, more expansive, more complex ones. Older systems do not disappear, but are subsumed within the more elaborate ones and can be reactivated when older problems resurface. Each new emerging system 'transcends and includes' the previous ones [10].

A second notion regarding emergence lies in the intangible aspects 'below the surface' that influence human behaviour. The core question according to Beck and Cowan is "how does the mind process reality". The framework structures thinking systems within people, not types of people. Each value system is associated with a specific 'world view', thus generating multiple 'truths'.

\subsubsection{Cyclical}

The development of value systems occurs in a fixed order. The value systems can be tagged as follows: Survival; Security; Energy \& Power; Order; Success; Community, Synergy and Holistic Life System. These systems brighten or dim along with changing life conditions and one's capacities. Each new value system includes and transcends the previous ones, thus forming a natural hierarchy (or holarchy).

The value systems alternate between I-oriented and we-oriented systems, with a respective focus to changing the world outside and coming to peace with the world inside.

\subsubsection{Double Helix}

Value systems develop in reaction to specific environmental challenges and threats: the systems brighten or dim when life conditions change. These Life Conditions (LC) consists of historic Times, geographic Place, existential Problems and societal Circumstances. As with the double helix in a DNA-string, Graves' model distinguishes LC as one of the two determining factors that cause the existence of prevailing and emerging contexts. The other one is Mind Capacities [MC's]. Their interactions produce the thinking systems, mentioned above.

Transformations to more complex contexts actually occur when life conditions have build up a sufficient level of urgency among entities to leave behind their proven pa- 
Table 2. A developmental approach to values.

\begin{tabular}{|c|c|c|c|c|}
\hline Development Label & $\begin{array}{c}\text { Compliance-driven Order } \\
\text { (Blue) }\end{array}$ & $\begin{array}{c}\text { Profit-driven } \\
\text { Success (Orange) } \\
\end{array}$ & $\begin{array}{c}\text { Care-driven } \\
\text { Community (Green) }\end{array}$ & $\begin{array}{c}\text { Systemic-driven } \\
\text { Synergy (Yellow) }\end{array}$ \\
\hline $\begin{array}{l}\text { Environment } \\
\text { LC }\end{array}$ & $\begin{array}{l}\text { Ordered relationships re- } \\
\text { quiring legitimization in } \\
\text { order to ensure stability and } \\
\text { security for the future }\end{array}$ & $\begin{array}{l}\text { Many viable alternatives for } \\
\text { progress, prosperity and } \\
\text { material gain since change is } \\
\text { the nature of things }\end{array}$ & $\begin{array}{l}\text { The gap between people and } \\
\text { their (material) possibilities } \\
\text { has become disproportion- } \\
\text { ately large }\end{array}$ & $\begin{array}{l}\text { Complex problems that } \\
\text { cannot be solved within the } \\
\text { current systems as awareness } \\
\text { of broad interconnections } \\
\text { grows. }\end{array}$ \\
\hline Values examples & $\begin{array}{l}\text { Duty, obedience, loyalty, } \\
\text { guilt, discipline, stability, } \\
\text { clarity, justice, one truth }\end{array}$ & $\begin{array}{l}\text { Productivity, personal es- } \\
\text { teem, image, reward, satis- } \\
\text { faction, competition }\end{array}$ & $\begin{array}{l}\text { Harmony, equality, consen- } \\
\text { sus, honesty, openness, trust }\end{array}$ & $\begin{array}{l}\text { Insights, tolerance, long term } \\
\text { orientation, systems-thinking }\end{array}$ \\
\hline
\end{tabular}

tterns of behaviour and challenge their world view. They have to experience that current solutions are no longer adequate. In order to cope with the new life conditions, entities must have a supportive mind capacity to be able to match the new challenges life conditions offer and generate new adequate behavior and subsequent institutional arrangements.

Entities such as people and organizations will eventually have to meet the challenges their context provides or risk the danger of oblivion or even extinction. If for instance societal circumstances change, inviting corporations to respond and consequently reconsider their role within society, it implies that corporations have to re-align their value systems and all their business institutions (such as mission, vision, policy deployment, decisionmaking, reporting, corporate affairs, etcetera) to these new circumstances.

\subsubsection{Adult}

Graves restricted the outcomes of his theory to 'healthy adults' only. In practice one can observe that Spiral Dynamic thinking can also be applied to the development of children, all be it with some adjustments. As a third generation researcher, with Graves being the first and Beck and Cowan the second generation, van Marrewijk applies the theory also to groups, organisations and even societies and economic systems, as this paper will demonstrate.

\subsubsection{Biopsychlogicalsocial}

People tend to change their biopsychlogicalsocial beings as their Conditions of Existence change. With respect to the biological appearances, it obviously applies to the pre-historic Cro Magnon, the Pygmies, Inuits and Bedouins, as well as contemporary Salarymen. Over time mankind was able to alter his DNA information to adjust to changing circumstances and support new generations with a better constitution to cope with prevailing circumstances. Also psychologically and socially people change along with their life conditions, creating new cultural patterns and institutional arrangements that facilitate adequate behaviour.

Psychologically, people alternate between an inner locus of control with a focus on changing and controlling the world outside (the I-systems) and an outer locus of control with a focus on coming to peace with the world inside (we-systems).

Due to the ability to match MC with LC, people centralized in a value system are psychosocially congruent with components of that system. On the other hand, a person may not be equipped to move to a more complex system, even if the Conditions of Existence demand it. Psychologically, these people remain 'arrested' towards future needs or even 'closed' to less complex value systems that, naturally, should have been included in their repertoire.

Individuals and groups develop and apply values and supporting institutional structures, in order to cope with the prevailing challenges. A person may stabilize at one or at a combination of value systems if the Conditions of Existence are stable. When LC warrants, a person or group may regress to a previous value system. As with an uphill ride, people back shift to a lower gear to get more power.

\subsubsection{Systems Development}

Each value system includes a range of positive and negative characteristics and behaviours, adaptive and maladaptive elements. A system can become healthy and unhealthy, supportive and destructive, energizing and frustrating, sowing the seeds of change. It offers linkages to change management, what to do in order to improve performance.

It is important to understand that $\mathrm{NO}$ value system is inherently "better" or "worse" than another. It is all about adequateness or appropriateness to the milieu and conditions of existence. As higher value systems normally include the previous contexts, a higher system is not simply better; it offers more grades of freedom to match particular challenges. If a response can be made adequately in a basic context, there is no need to do it more sophistically and waste time and efforts. Moreover, complex value systems are much more vulnerable, or more difficult to sustain.

The actual introduction to the various levels of existence will be dealt with in the next paragraph.

\subsection{Wilberian Approach to Development}

In Sex, Ecology and Spirituality, Ken Wilber [10] made a large contribution to evolutionary developments. He 
supports Graves when stating: "Evolution proceeds irreversibly in the direction of increasing differentiation/ integration, increasing organization and increasing complexity". This "growth occurs in stages, and stages are ranked in both a logical and chronological order. The more holistic patterns appear later in development because they have to wait the emergence of the parts that they will then integrate or unify ${ }^{2}$. This ranking refers to normal hierarchies (or holarchies) converting "heaps into wholes, disjointed fragments into networks of mutual interconnection",

As the natural orientations emerged, they clearly show an increase of integratedness and complexity, each stage including and transcending the previous ones.

From evolutionary literature, Wilber concludes twenty "patterns of existence" or "tendencies of evolution" which are summarized below: reality is not composed of things or processes; it is not composed of wholes nor does it have any parts. Rather it is composed of whole/parts, or holons ${ }^{4}$. This is true of the physical sphere (atoms), as well as of the biological (cells) and psychological (concepts and ideas) sphere, or simply said, apply to matter, body, mind and spirit. Atoms or processes are first and foremost holons, long before any 'particular characteristics' are singled out by us.

Holons display four fundamental capacities: selfpreservation, self-adaptation, self-transcendence and selfdissolution. Its agency — its self-asserting, self-preserving tendencies - expresses its wholeness, its relative autonomy; whereas its communion - its participatory, bonding, joining tendencies - expresses its partness, its relationship to something larger. Both capacities are crucial: any slight imbalance will either destroy the holon or make it turn into a pathological agency (alienation and repression) or a pathological communion (fusion and dissociation). Self- transcendence (or self-transformation) is the system's capacity to reach beyond the given, pushing evolution further, creating new forms of agency and communion. Holons can also break down and do so along the same vertical sequence in which they were built up.

These four capacities or 'forces' are in constant tension: the more intensely a holon preserves its own individuality, preserves it wholeness, the less it serves its communions or its partness in larger and wider wholes and vice versa. This tension can be manifested, for instance in the conflict between rights (agency) and responsibilities (commun ions), individuality and membership and autonomy and heteronomy.

If holons stop functioning, all the higher holons in the

\footnotetext{
${ }^{1}$ Wilber, K., Sex, Ecology and Spirituality, Shambhala, second edition. 2000, 1995 (page 19, 74).

${ }^{2}$ Wilber, K. SES (page 28) italics by Wilber.

${ }^{3}$ Wlber, K. SES (page 26).

${ }^{4}$ Koestler:" a holon is a whole in one context and simultaneously a part in an other".
}

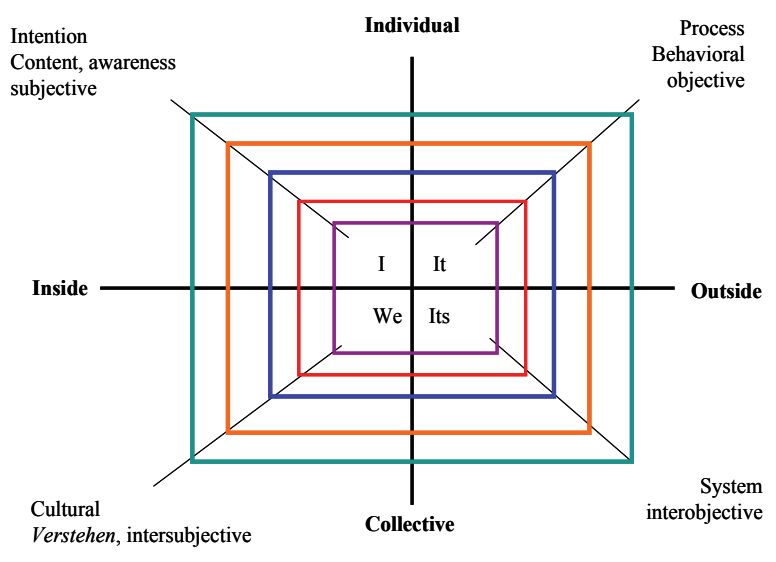

Figure 1. Wilber's all quadrant model, slightly adapted.

sequence are also destroyed, because those higher wholes depend upon the lower as constituent parts. We might say that Wilber as well as Graves, Beck \& Cowan have created an almost identical phase wise orientation to reality however based on different lines of reasoning.

Wilber's rich analysis of science and (eastern) religion has culminated in a four-quadrant perspective towards Reality. The upper quadrants represent individual holons, the lower half of the diagram, social or communal holons. The left side is the interior and the right side the exterior form or structure of holons.

The upper-right quadrant represents the objective, empirical observations of holon behaviour, such as atoms, gases, fish or humans. The upper-left quadrant stands for the I-world: the interior form of an individual holon: subjective intentions and awareness. Characteristic sciences focused on this quadrant are psychoanalysis, phenomenology and mathematics. The lower-right quadrant represents the 'its-world'. With reference to humans, it shows the exterior forms of social systems such as the development from kinships to nations-states, but also tools and technology, architectural styles, forces of production, concrete institutions and even written material. The lower-left quadrant corresponds with the we-perspective of Reality, the Cultural dimension. Weber introduced an intersubjective sociologist approach, Verstehen, that characterizes this quadrant. It is the realm of relational exchange creating collective values, consciousness, worldviews and common meaning and interpretations.

The upper quadrants coincide with Graves' Biopsychosocial features of the Mind Capacity and the lower ones with Life Conditions. In both concepts, the quadrants are aligned: Each point in any of these quadrants correlate with a specific set of points in the other quadrants, such as Figure 1 above demonstrates. The Four Quadrant Model includes Graves' Levels of Existence as Table 3 shows.

Woodsmall has labeled the right quadrants as Process and System. It aligns better with the intention to apply the Quadrants Model to corporate dynamics. 


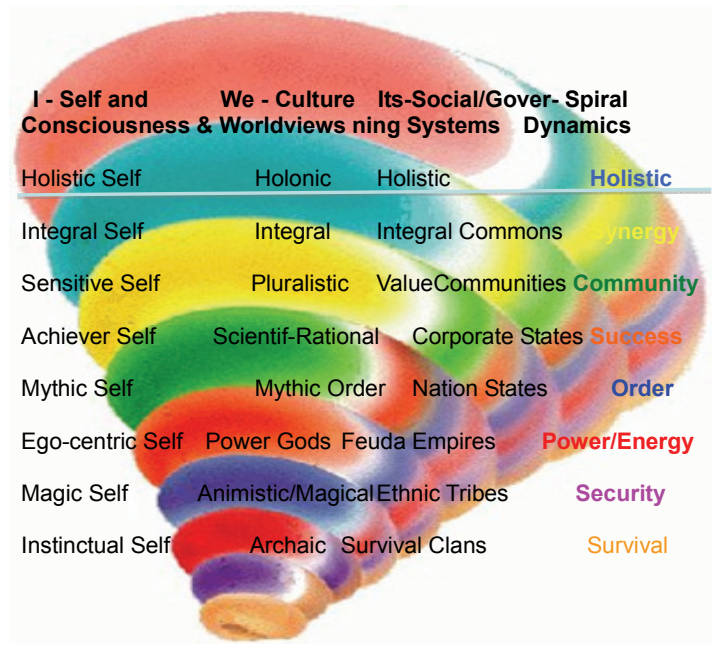

Table 3. Quadrants as process and system.

\subsection{Application to Corporate Dynamics}

Organizations and employees can be recognized easily as holons, as they are mutually dependent, as strikes and absenteeism clearly show. In terms of Wilber, organizations tend to support their employees (vertical relationship), creating value as an (horizontal) agency, in constant exchange with its stakeholders (horizontal communion).

Challenged by changing circumstances and provoked by new opportunities, individuals, organizations and societies develop adequate solutions that might be new sublimations, creating synergy and adding value at a higher level of complexity. Since instability increases at higher complexity levels, entities can shift to lower levels should circumstances turn unfavorable or should competences fail to meet the required specifications.

Figure 2 represents a phase-wise development of corporations, as complexity increases thus requiring additional degrees of freedom to find more adequate solutions to prevailing circumstances. Along with the evolutionary development of corporations their awareness, their culture, their behavior and their structures/systems change.

Clusters of values facilitate these institutional changes and manifestations. Evolutionary development has reveal-

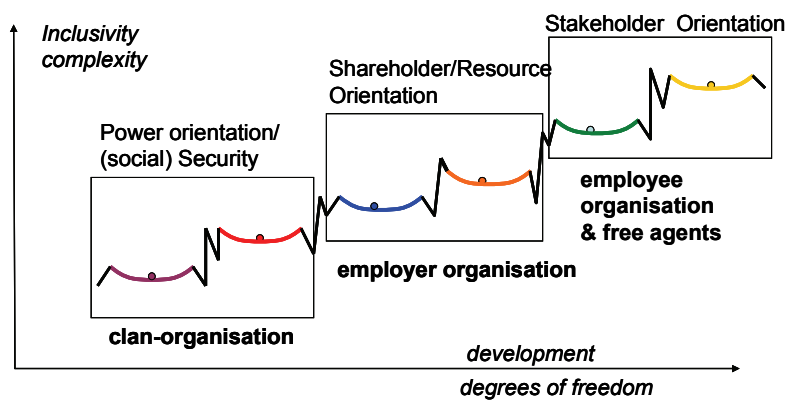

Figure 2. Phase wise orientation to business development. ed a sequence of multiple levels or development stages. From now on we will refer to these as the contexts of organizations. In order to be able to draft ideal type organizations, aligned with specific contexts, we need to go deeper and explore the disciplines that are active within organizations. We need to elaborate on the various manifestations disciplines can take in various contexts. We therefore introduce the Global Excellence Model.

\section{Supportive Structures of the Cubrix: Disciplines}

\subsection{Global Excellence Model}

The European Model for Business Excellence (EFQM model) [11], developed in 1991, was a breakthrough in management and quality improvement, and has been applied successfully among thousands of companies, mainly all over Europe. Over time such initiatives become rigid, as they appear to be unable to include new developments in their conceptual thinking and business appliances. Their failure to include a phase-wise approach caused us to develop the Global Excellence Model (GEM). However, the resemblances are much more important, than the differences. See www.efqm.org for further information.

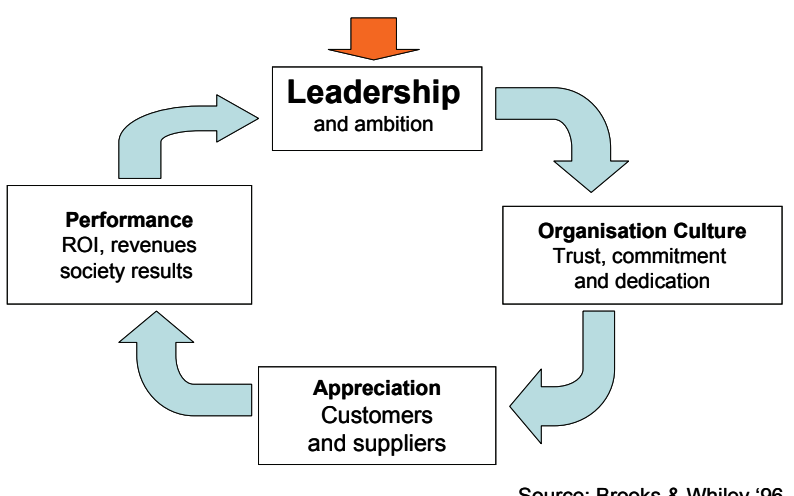

Figure 3. Linkage research by brooks \& whiley' 96.

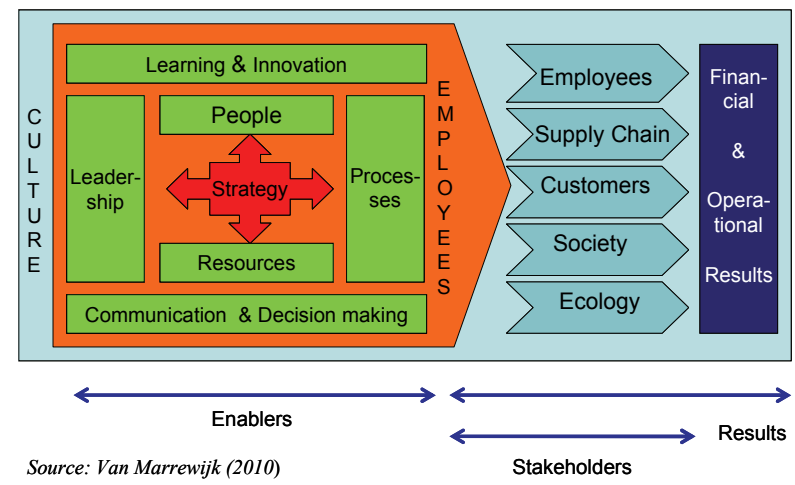

Figure 4. Global excellence model(GEM). 


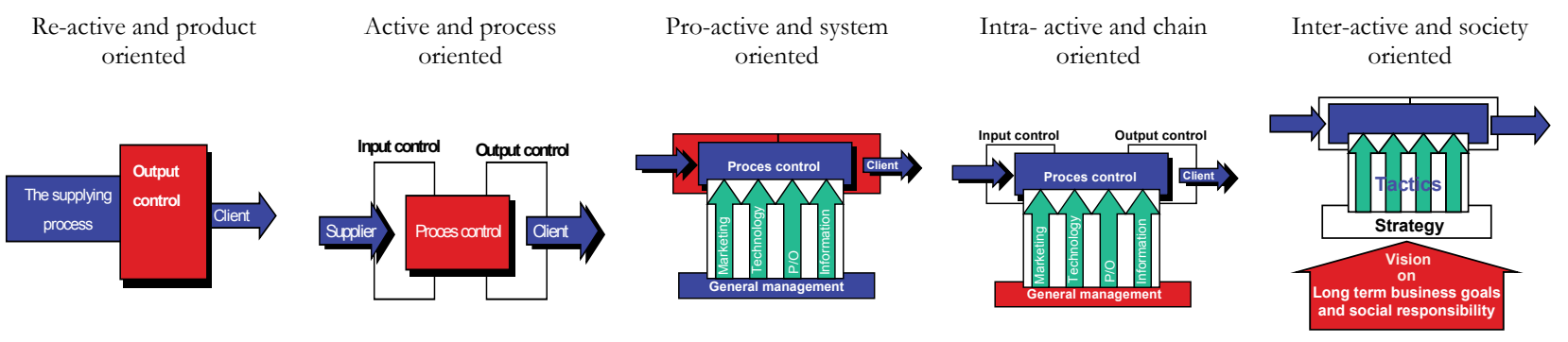

Figure 5. INK quality orientations.

The GEM as well as the EFQM model is non-pre scriptive frameworks that recognizes that there are many approaches to achieving sustainable excellence. Due to their focus on excellence, the EFQM model is centred on process management. We prefer to align the GEM with Brooks and Whiley's conclusions based on Linkage Research (1996) and to focus on the impact of leadership and culture. It is people who bring passion, loyalty, entrepreneurship, trust and dedication to the work floor. Without these, processes would never achieve the expected levels of output. As Wilber taught us, it is all about balancing and consistency in order to deliver adequate solutions to prevailing circumstances.

A group of people create, plan, deploy, lead, implement, improve, execute, learn, enjoy, what ever that needs to be done, in order to achieve the desired results. These results can only come about when stakeholders appreciate the fruits of their doing. Thus, the enabler criteria cover what an organization does, while the results criteria cover what an organization achieves. See Figure 4.

The major distinction between the GEM en the EFQM model is the GEM's ability to generate multiple levels of quality development, both with respect to contexts as well as situations.

This issue of multi-levelledness was firstly challenged by the Netherlands Quality Institute (INK), already in 1993, when they introduced five quality orientations for assessment purposes: activity (or output), process, organization (or system), chain and society.

Each next quality orientation transcends and includes the previous ones, evidently increasing its complexity. The issue here is "do quality orientations align with the Grave-sian development levels or can these value systems (or contexts) support various quality orientations."

In Table 4, Van Marrewijk presents his conclusions: he INK quality complexity phases do not align necessarily with the Gravesian framework of development levels. An organization functioning in Order is adequate with output control (X), and has abilities with respect to managing processes (x). Organizations that are strong in Success are better able to manage their processes $(\mathrm{X})$ and have abilities to define and apply quality in systemic terms (x). Less complex contexts might have limited abilities or none at all to produce more complex quality orientations $(\mathrm{O})$.

In order to support an organization wide approach to quality, processes and systems need to be complemented by, firstly, a culture that creates unity, trust and supports co-operation and, secondly, an approach that generates (personal) alignment of the stakeholders involved.

In trying to improve quality it makes quite a difference if a shift to a next quality orientation can be achieved within the same context, or that a transformation to a more complex value system is necessary. We believe that many advisors in quality improvement have failed in making this distinction and taking proper precautions.

Van Marrewijk therefore suggests defining quality orientations as 'situations' within a context, at the same time acknowledging the developmental aspects of qualitystating that specific orientations can be best imple more straight-forward than in organizations supported by the value system Success. Managers and advisors alike have often questioned the lack of simplicity in our approach. There is lots of evidence in the failure of numerous quality

Table 4. The quality matrix.

\begin{tabular}{|l|c|c|c|c|}
\hline $\begin{array}{l}\text { Contexts/Qu } \\
\text { ality } \\
\text { Orientations }\end{array}$ & Order & Success & $\begin{array}{c}\text { Commu- } \\
\text { nity }\end{array}$ & Synergy \\
\hline Output & $\mathrm{X}$ & $\mathrm{x}$ & $\mathrm{x}$ & $\mathrm{x}$ \\
\hline Process & $\mathrm{x}$ & $\mathrm{X}$ & $\mathrm{x}$ & $\mathrm{x}$ \\
\hline Organisation & - & $\mathrm{x}$ & $\mathrm{X}$ & $\mathrm{x}$ \\
\hline Chain & $\mathrm{O}$ & - & $\mathrm{x}$ & $\mathrm{X}$ \\
\hline
\end{tabular}

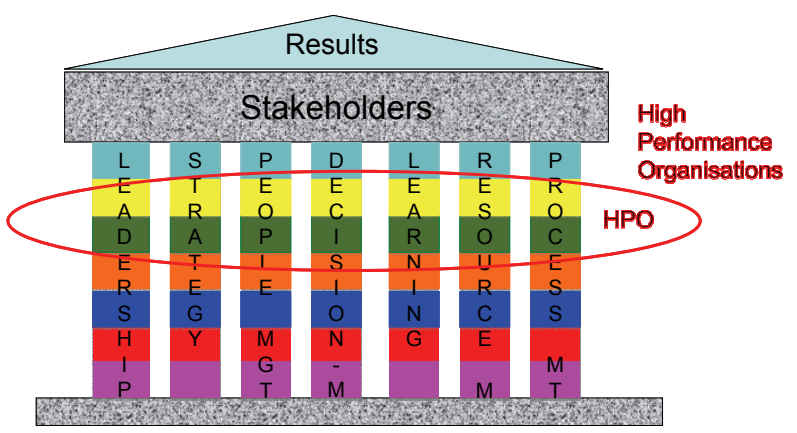

Figure 6. Global excellence model (GEM) and SDI phases. 
improvements projects. People have to get used to it that managing complex organizations requires large skills and good theories, better than we ones they used to apply. In elaborating on the performance cycle, we will further deal with this topic.

In developing the GEM, we have assigned the various quality orientations as subsequent manifestations of process management, one of the seven enablers within organizations. We applied the same approach to all seven enablers, thus providing the image of a temple with seven pillars, see Figure 6, each consisting of a set of subsequent paradigms.

In Subsection 4.2 we will demonstrate how these 'pillars' support specific research tools and related implementation and learning activities.

\subsection{The Cubrix}

The Cubrix, as well as its supportive concepts, emphasize the relationship between performance and organization development. With a single focus on management areas, companies do make progression when they succeed in aligning various enablers into an integral business approach, but often they fail in sustaining their performance growth due to rigidness with respect to organizational development. Once organizational development also becomes a variable in improvement activities, sustainable progress is possible. In discussing High Performance Organizations we will further elaborate on this topic.

The Cubrix shows the three dimensions: Organization Development (levels), Disciplines (Management Areas, enablers) and Stakeholder Performances (or Triple Bottom Line: People, Profit, Planet). Each of the cells within the Cubrix can be highlighted and made specific. The result is the so-called Transition Matrix. The appendix shows a summarized version of this matrix.

In the next chapter, Van Marrewijk will demonstrate some of the research tools based upon the Cubrix.

\section{The Cubrix: Supporting Research}

\subsection{Research to Improve}

Successful organizations have long stopped running on just processes, numbers and systems. Their measurement systems also include organizational culture and employee intentions. Driven by values and ambitions and challenged by competition, organizations look for the right blend of 'hard' and 'soft' measures in order to continuously improve corporate performance and successfully implement a carefully drafted road map for organizational development.

Research to Improve's surveys, monitors, scans and assessments provide a deep understanding of dynamic and complex topics within organizations. The research tools

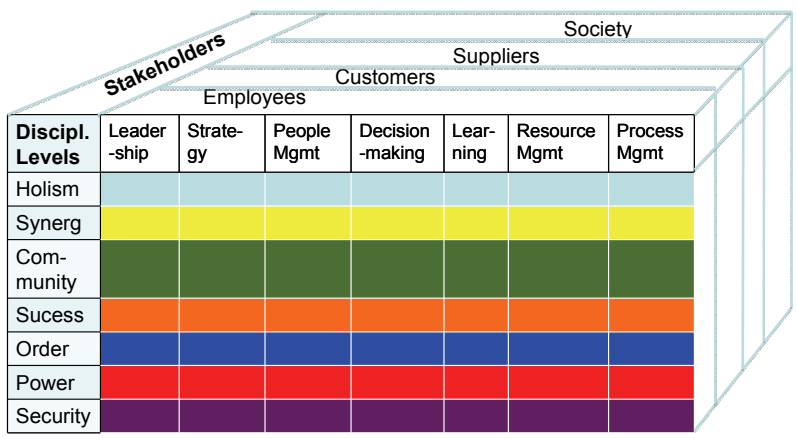

Figure 7. The cubrix.

generate results, which give an insight into what people do, how and why they do so and what steps managers and employees can take in order to achieve goals, overcome bottlenecks and enhance performance.

Each development phase has a specific culture and values, ambitions, set of characteristic institutions and related change strategies. Research to Improve has developed research tools for every development phase and within every phase, for each management criteria. By means of generic surveys and dedicated scans, Research to Improve tries to investigate the dominant contexts within an organization. Sophisticated research, strengthened with conceptual and practical expertise, generates a proper diagnosis. This should blend with the internal experiences through dialogues and 'good conversations' discussing and interpreting the contemporary contexts and situations, challenges and bottlenecks. This is the input for drafting the best way to move ahead.

The outcomes of generic surveys are presented in feedback reports and graphs based upon Spiral Dynamics, $4 \mathrm{Q}$ model and the GEM. Which policies and business topics are managed best and appreciated most? Are the four quadrants consistently developed?

In the next paragraph we will introduce examples of research tools, such as the RTI Survey, the Leadership Monitor and the People Management Monitor.

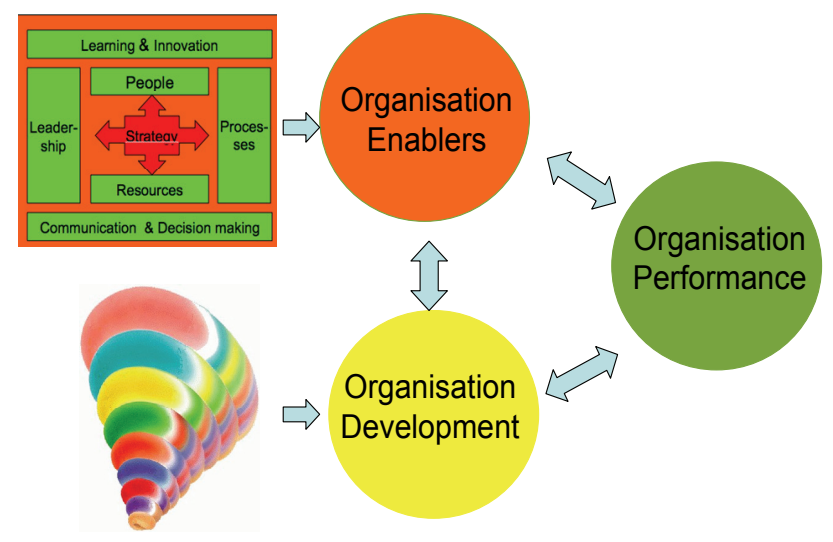

Figure 8. Research to improve model (Cubrix). 


\subsection{Research to Improve Basic Employee Perception Survey}

The RTI Survey identifies the management areas of the GEM, the dominant context, situation and bottlenecks in management and operation. It reports the results on the three most prominent performance criteria: Good Entrepreneurship, Good Employership and Good Neighborship.

The feedback report generates the opinions and perceptions of stakeholders-mostly employees-with respect to:

- The quality of leadership

- The guidance of the strategy

- The effectiveness of communication and decisionmaking.

- People management

- The way learning, collaboration and innovation takes place

- The support of resources and opportunities

- The quality of the processes

As well as cultures and the development levels

The RTI Survey emphasizes the importance of trust, as trust includes and transcends employee satisfaction, motivation and commitment.

As custom-made adjustments we can include the core values of the clients' organization and report if the desired behavior not only meet the requirements, but also whether it matches the intrinsic values of the employees, and if it is sufficiently supported by their culture, by leadership behavior, and by the policies and procedures provided by the organization itself.

The RTI survey links to organizational performance to organization development, so that long-term aspirations can be made specific to day-to-day operations. Also the gap between 'what is' (ist) and 'should be' (soll) can be better understood. Combined, one can design a roadmap, by distinguishing a sequence of steps, priorities and interventions. See also Subsection 5.1.

In 2009, Research to Improve developed an innovative research tool for another stakeholder group, hospital patients by once more applying spiral dynamics thinking into the monitoring of vital processes in hospital management: the patient trust survey, we were able, among others, to distinguish levels of patients' wellbeing, their loyalty, quality perceptions from patients' perspective and various ways how medical and nursing professionals behaved towards the patients.

\subsection{Leadership and People Management}

The Cubrix suggests seven leadership styles, each associated with a specific development level (Figure 9). Per style, experts of the Rotterdam School of Management, Erasmus University, especially dr. Dirk van Dierendonck, dr. Daan Stam and dr. Inge Nuijten, selected leadership qualities. The statements defining these qualities are validated via scientific methods.

An effective leader, let us say one with a natural gift in servant leadership, should firstly align with the context and challenges the organisation is facing and secondly, include the qualities of the previous leadership profiles. In addition to the congruency of leadership competences, the monitor is able to measure the contextual effectiveness of specific leaders. In the end we do not want to have an entrepreneur responsible for accountancy or a bookkeeper for an R\&D department. The situational effectiveness of leaders is determined by the strategic orientation of the organization. See also Subsection 4.4.

The People Management Monitor is developed in order to provide in-depth understanding of the effectiveness of an organisation's people management practices and policies. Based on the Cubrix, Research to Improve distinguished five ambition levels in people management policies:

1) Creating a safe, vitalizing and physically and emotionally healthy community (building the foundation for a culture of trust);

2) A clear and fair salary payment system, employee benefits, and working conditions (Personnel Administration Department);

3) Employee fit in a functional perspective, especially the recruitment, career development and employee turnover, as well as work pressure and absenteeism (Human Resource Management);

4) Investing in employees' professional and personal development (Human Talent Management), by attracting and attaching employees;

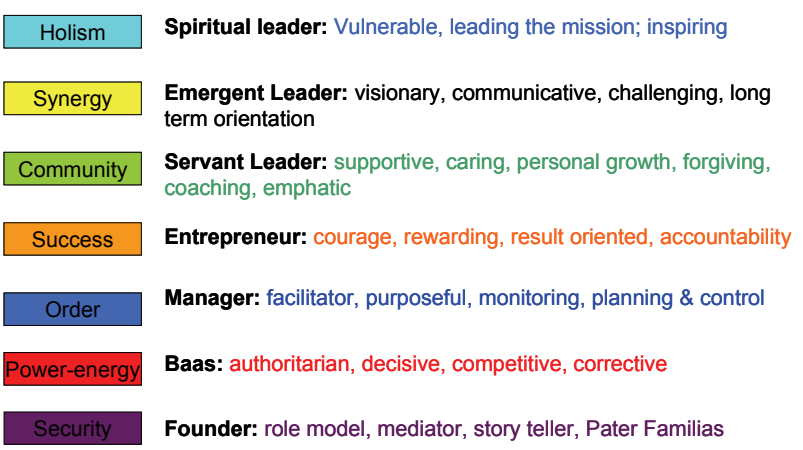

Figure 9. Value driven leadership styles and qualities.

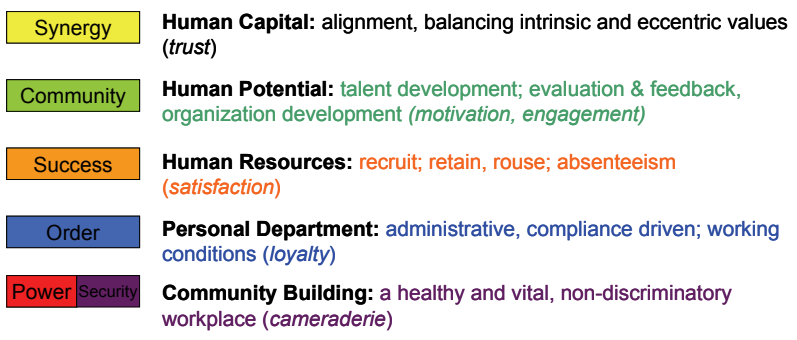

Figure 10. Value driven people management policies. 
5) Fine-tuning personal drives and qualities and collective ambitions, for daily operational fit, cultural alignment as well as matching individual and collective learning needs (Human Capital Management). These instruments provide a sense of consistency: "what will be the results when we stick to an authoritarian leadership style, with our business attracting more and more educated and independent employees?" "How can we support employees' dedication, engagement and motivation, as these are one of the most important success factors for High Performance Organisations?"

With a better understanding of contexts, values, challenges and organization development, companies can select more effective interventions and improvement activities.

\subsection{High Performance Organizations-HPO}

Jim Collins, co-author of Build to Last [12] and author of Good to Great [13], has revealed how good, mediocre and even bad companies achieve enduring greatness, and sustain their success over time by 'engineering' growth and continuous improvement into the DNA of an enterprise. Measured according the number of copies sold, the books were a huge success, but only a few companies seem to be able to apply the findings in practice.

Dr. André de Waal, a Dutch scientist and business consultant, performed a five-year study to grasp the discriminating factors for High Performance Organisations (2008). He defined five pillars:

- High quality of management

- High quality of professionals

- Long term orientation

- Open and action oriented

- Continuous Improvement

The specific qualities of leadership relate to what we called servant and emergent leadership, the green and yellow realms of organization development (see Figure 6). The same applies to professionals: they flourish in cultures of trust. If fully enabled, respectfully challenged and endowed with opportunities to take responsibility, professionals can become highly resilient, dedicated, and profoundly more productive than employees working in

Table 5. The strategy matrix.

\begin{tabular}{|l|c|c|c|c|}
\hline $\begin{array}{l}\text { Contexts/Str } \\
\text { ategic } \\
\text { orientations }\end{array}$ & Order & Success & $\begin{array}{c}\text { Commu- } \\
\text { nity }\end{array}$ & Synergy \\
\hline Effectiveness & $\mathrm{x}$ & $\mathrm{X}$ & $\mathrm{x}$ & $\mathrm{x}$ \\
\hline Efficiency & $\mathrm{X}$ & $\mathrm{x}$ & $\mathrm{x}$ & $\mathrm{x}$ \\
\hline Flexibility & $\mathrm{x}$ & $\mathrm{x}$ & $\mathrm{X}$ & $\mathrm{x}$ \\
\hline Creativity & $\mathrm{x}$ & $\mathrm{x}$ & $\mathrm{x}$ & $\mathrm{X}$ \\
$\begin{array}{l}\mathrm{X}=\text { dominant } \\
\mathrm{x}=\text { applicable }\end{array}$
\end{tabular}

organizations offering mediocre conditions.

The GEM adds two additional criteria and combined with its phase-wise orientation, Research to Improve is quite able to measure HPO and identifying the intermediate steps in order to enter a new level of performance and ultimately becoming a HPO.

The next tool, the strategy scan, developed by Marcel van Marrewijk and Prof.dr Teun Hardjono, shows how this can be done.

\subsection{The Strategy Matrix}

The first step in drafting a roadmap towards sustainable performance improvement and organisation development is finding out one's position. What are the current constraints, challenges and risks? What are the dominant value systems within the organisation? In short, what (strategic) situation and context are most adequate to face current strengths and weaknesses, opportunities and threads?

In 2003 Van Marrewijk and Hardjono developed the Strategy Scan, based on the Strategy Matrix. This online scan supports the strategic dialogue, the exchange of facts and experts opinions, and gives a direction to strategy development. One can conduct the Strategic Scan in board of directors, management teams, among staff members, and as a vertical dialogue deeper into the organisation as well as outside, even with all stakeholders.

The first part of the scan focuses on strategic situations, which ultimately determine the main direction or strategic orientation of the organisation. Examples of such aspects are the consumer needs and the current bottleneck obstructing organisational performance. The result is a focus and a set of ideal type interventions. See also Van Marrewijk [7].

The second part surveys the nature and complexity of the (external) environment and the disciplinary developments (or paradigms) regarding the management criteria such as leadership, people -, resource - and process management. The Strategy Scan indicates the organisation's most dominant development phase, its favourite level of existence.

A Strategy Matrix can be drawn with all situations and contexts. In contradiction to the quality situations, all strategy situations are relevant to all contexts, but in each context a situation is manifested differently. The large $\mathrm{X}$ indicates the natural combinations. Efficiency can be performed adequately in Order, while Effectiveness aligns best in Success, etcetera.

Each combination provides the researchers and corporate experts a set of specific interventions and key performance indicators, which forms a major input for drafting a roadmap for performance improvement, aligned with the dominant value systems of the organisation. 
The Strategic Sustainability Scan is an extended version including sustainability issues. The Sustainability Scan generates an adequate meaning of corporate sustainability and responsibility, an ideal type reference on which an organization can develop its own touch and approach. This way one can link strategy with CS/CRpolicies and interventions.

\section{The Cubrix Supporting Change Management}

From the sheer construction of the Cubrix, in other words, through distinguishing contexts (value systems), aspects (disciplines) and situations (quality or strategic orientations) one have to conclude that all management principles, models and even hypes have their value, but often only in a certain combination of situation, aspect and/or context. Or put differently: each cell within the Cubrix will have a list of do's and don'ts, with effective approaches, tools and policies, and ones that do not apply to this particular context-situation.

Due to changing circumstances both outside as well as inside organizations, in the case of corporate dynamics, models, tools and certainly hypes have limited applicability and tenability over time. The Cubrix is therefore able to function as a framework for structuring tools, policies, models and management literature.

The multi-level approach underlying the Cubrix also revealed a set of distinctive complexity levels in change management. Furthermore, it offers a conceptual basis for the so-called Performance Improvement Cycle from which one can deduct a roadmap for sustainable business improvement and organisation development. It is the topic for our next paragraph.

\subsection{The Performance Cycle}

The Cubrix helped us in structuring change management into four distinctive hierarchical complexity levels: (1) vitalising, (2) optimising, (3) shifting and (4) transforming. These four dimensions of change management are explained below.

\subsubsection{Vitalizing}

Often the performance can be improved by enhancing the fundamental skills, structures and procedures of including contexts; these interventions are relatively simple as we have a lot of experience in managing these aspects, but being involved in more complex value systems, we tend to neglect basic competences although they can jeopardize current performance potential.

Vitalization programs ought to touch all four quadrants, or at least restore the balance between them.

\subsubsection{Optimizing}

Once a sound fundament has been realized, further im- provement can occur we organizations enhance the effectiveness of the characteristic institutions within the dominant context. Try to find out and apply best practices, work smarter and excel in what needs to be done.

\subsubsection{Shifting}

If including and current contexts are functioning well, further improvement can be established by fine-tuning the strategic situation. Within a context, organizations must focus their business towards the most adequate situations, aligning their interventions accordingly.

\subsubsection{Transforming}

When the previous three change management dimensions can no longer sustain corporate performance, organizations should adopt new ways of organizing by transforming to a more complex context, adopting emerging value systems and all institutions aligned with it. Transformations are complex phenomena, especially if managed as an improvement project.

Each value system has a supporting institutional structure that consistently arranges ways of doing. As more value systems appear parallel, or nested, within organizations, these structures are reasonably flexible to comprehend elements from various value systems. Elements of emerging systems can be developed within the current structures. It needs to have a critical mass of people who can support these values and corresponding awareness and behaviour. Once these values are triggered by challenges or intrinsic motives, their full potential can become manifest causing new institutional arrangements, encompassing previous ones. These transformations are far from simple. Changing life conditions boost a sense of urgency, building up a dissonance, a pressure to move, a necessity to change, and requires commitment to change at the top of the organization. These necessary conditions can be concerted into a successful transition to a more complex level of existence. Despite its difficulty, some organisations are very good at it [14].

Having identified the four dimensions of change management, we adapted the Performance Improvement Cycle. See Figure 11. It is structured according to Deming's Plan-Do-Check-Improve sequence.

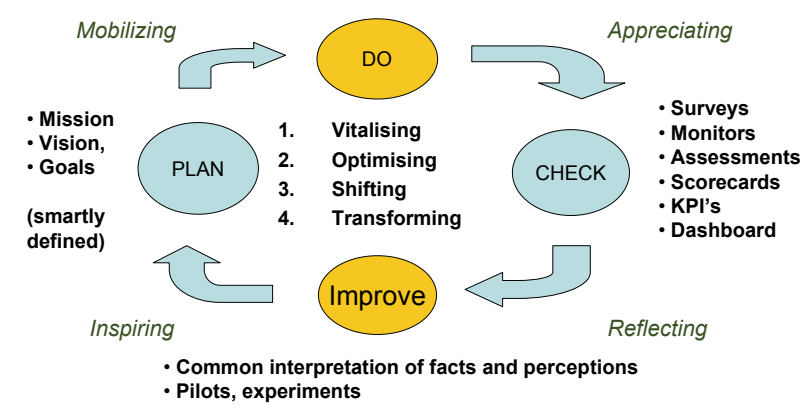

Figure 11. Performance improve cycle, based on deming's PDCA. 
The Performance Improvement Cycle suggests various ways to check the impact of the implementation process. Employee perception tools, such as surveys, monitors and assessments, as well as quality management, business operation and accounting tools generate data which via business intelligence services are provided to the board of directors, to management and professionals. Together they interpret the data and determine the progress made. Easy adaptation and fine-tuning is implemented directly, but larger alterations can be tried as experiments and pilots on a small-scale basis, or postponed until they fit the next strategic orientation.

\subsection{A Roadmap towards Sustainable Performance}

Deducting a roadmap for performance improvement and organizational development can be difficult as each organisation is unique. Many aspects can play a role and not all of them can be foreseen. Still it makes sense to have an idea about the path of change. What can we expect? What level of complexity? Do we have the necessary competences? Do we have the right people on the bus?

Each organisation must provide its own answers, but at least, by applying the Strategy Scan, the Strategy Matrix and the Performance Improvement Cycle, one can grasp its position, its strategic focus, a set of adequate interventions in order to lift the organisation's bottlenecks and enhance its basic competences, and its dominant context to 'colour' the interventions into fitting change activities.

Good surveys can provide management information from which one can tell if vitalisation or optimisation is most effective to enhance corporate performance. Frequently held strategic analyses can provide arguments to remain focused or shift to a next strategic orientation, prioritising a new set of interventions. Strategies can shift permanently within one context. This is relatively simple, but challenging enough.

\section{Building up Experiences}

Since 2000, Van Marrewijk is engaged in building an integral, multi-level management framework. Now it is in operation. Several research methods have been based upon the Cubrix and consultancy firms are currently applying the new understanding in change management, performance improvement and organisation development.

Supported by our state-of-the art research platform we are able to enable researchers worldwide with our techniques, software and research methods. This will boost our experience and further development of our methods and understanding. This is an invitation to join our efforts in trying to build better businesses and a better society.

\section{References}

[1] M. van Marrewijk, "European corporate sustainability framework," In International Journal of Business Performance Measurement, Vol. 5, Nos. 2/3, pp. 213-222, 2003.

[2] M. van Marrewijk, "The social dimension of organizations: Recent experiences with great place to work ${ }^{\circledR}$ assessment practices," In Journal of Business Ethics, Vol. 55, No. 2, pp. 135-146, December 2004.

[3] "Excelleren in de weerbarstige praktijk: Knelpuntenonderzoek toepassing INK-managementmodel," ERBS BV/Erasmus University, 2001.

[4] M. van Marrewijk, "Concepts and definitions of corporate sustainability," In Journal of Business Ethics, Vol. 44, No. 2 and 3, pp. 95-105, May 2003.

[5] M. van Marrewijk and M. Werre, "Multiple levels of corporate sustainability," In Journal of Business Ethics, Vol. 44, No. 2 and 3, pp. 107-119, May 2003.

[6] M. van Marrewijk, "A value based approach to organization types: Towards a coherent set of stakeholder-oriented management tools," In Journal of Business Ethics, Vol. 55, No. 2, pp. 147-158, December 2004.

[7] M. van Marrewijk and T.W. Hardjono, "The social dimensions of business excellence," In Corporate Environmental Strategy, Vol. 8, No. 4, 2001.

[8] M. van Marrewijk, I. Wuisman, W. de Cleyn, J. Timmers, V. Panapanaan and L. Linnanen, "A phase-wise development approach to business excellence: Towards an innovative, stakeholder-oriented assessment tool for organizational excellence and CSR," In Journal of Business Ethics, Vol. 55, No. 2, pp. 83-98, December 2004.

[9] D. Beck, and C. Cowan, "Mastering values, leadership and change," Spiral Dynamic, Blackwell Publishers ltd., Cornwall, 1996.

[10] K. Wilber, "Sex, ecology, spirituality: the spirit of evolution," Shambhala, Boston, 1995.

[11] "European foundation for quality management," At http://www.efqm.org.

[12] J. C. Collins and J. I. Porras, "Successful habits of visionary companies," Built to Last, Century, London, 1994.

[13] J. C. Collins, "Why some companies make the leap and other don't," Good to Great, Harper Business, New York, 2001.

[14] M. van Marrewijk, and H. M. Becker, "The hidden hand of cultural governance: The transformation process of humanities, a care-driven organization providing cure, care, housing and well-being to elderly people," In Journal of Business Ethics, Vol. 55, No. 2, pp. 205-214, December 2004. 


\section{Appendix}

\begin{tabular}{|c|c|c|c|c|}
\hline \multicolumn{5}{|c|}{$\begin{array}{c}\text { Transition Matrix Labels } \\
\text { based on Spiral Dynamics and Global Excellence Model }\end{array}$} \\
\hline $\begin{array}{c}\text { Development labels } \rightarrow \\
\text { Enablers : }\end{array}$ & $\begin{array}{l}\text { Compliance-driven } \\
\text { Order (Blue) }\end{array}$ & $\begin{array}{c}\text { Profit-driven } \\
\text { Success (Orange) }\end{array}$ & $\begin{array}{c}\text { Care-driven } \\
\text { Community (Green) }\end{array}$ & $\begin{array}{c}\text { Systemic-driven } \\
\text { Synergy (Yellow) }\end{array}$ \\
\hline Leadership & Manager & Entrepreneur & Servant Leader & $\begin{array}{l}\text { Emergent } \\
\text { Leader }\end{array}$ \\
\hline Strategy & $\begin{array}{l}\text { Dominance through hierar- } \\
\text { chies }\end{array}$ & $\begin{array}{l}\text { Autonomous growth due to } \\
\text { competitive qualities }\end{array}$ & $\begin{array}{l}\text { Stakeholder engagement; } \\
\text { Chain oriented }\end{array}$ & $\begin{array}{l}\text { Society oriented; seeking } \\
\text { breakthroughs }\end{array}$ \\
\hline $\begin{array}{l}\text { Communication \& Deci- } \\
\text { sion making }\end{array}$ & $\begin{array}{l}\text { Top down; Directive; Legal } \\
\text { procedures }\end{array}$ & $\begin{array}{l}\text { Still cascading, with room } \\
\text { for negotiations; good info } \\
\text { from the bottom is always } \\
\text { welcome }\end{array}$ & $\begin{array}{l}\text { Bottom-up; group de- } \\
\text { cides; Consensus based }\end{array}$ & $\begin{array}{l}\text { Top-down and bottom-up } \\
\text { balance; Holacracy; Con- } \\
\text { sent based }\end{array}$ \\
\hline People Management & $\begin{array}{l}\text { Personnel \& Administration; } \\
\text { Working conditions }\end{array}$ & $\begin{array}{l}\text { Human Resource Manage- } \\
\text { ment }\end{array}$ & $\begin{array}{c}\text { Human Talent Manage- } \\
\text { ment }\end{array}$ & $\begin{array}{c}\text { Human Capital Manage- } \\
\text { ment }\end{array}$ \\
\hline Learning \& Innovation & $\begin{array}{c}\text { Incremental (product) inno- } \\
\text { vations; knowledge and } \\
\text { competence management }\end{array}$ & $\begin{array}{l}\text { Process innovation, and } \\
\text { product diversification; } \\
\text { professionalization through } \\
\text { MD-training }\end{array}$ & $\begin{array}{c}\text { Social Innovations; } \\
\text { developing supportive } \\
\text { structures for organiza- } \\
\text { tional learning }\end{array}$ & $\begin{array}{c}\text { System innovations, based } \\
\text { on in-depth understanding } \\
\text { of corporate dynamics, } \\
\text { sustainability and needs }\end{array}$ \\
\hline Resource Management & $\begin{array}{c}\text { Procedural supply relations } \\
\text { based on strict pricing poli- } \\
\text { cies }\end{array}$ & $\begin{array}{l}\text { Maintenance on process } \\
\text { indicators }\end{array}$ & $\begin{array}{l}\text { Outsourcing with strong } \\
\text { relationships, peer audits }\end{array}$ & $\begin{array}{l}\text { Co-creating; together- win; } \\
\text { Sustainable Purchasing }\end{array}$ \\
\hline Process Management & Activity Orientation & Process Orientation & System Orientation & $\begin{array}{c}\text { Chain and Society Orien- } \\
\text { tation }\end{array}$ \\
\hline
\end{tabular}

\section{Notes}

1) The ECSF is a European-wide research project, financed under Article 6 of the European Social Fund Regulation. It has the aim to design Corporate Sustainable and Corporate Responsible (CS-R) ways of doing business. Within the project, a basic conceptual framework is developed, integrating several proven theories, in order for organizations to address and interpret CS-R. The EFQM model is one of the founding models of ECSF. Contact: marcel@vanmarrewijk.nl or +31.6.8 1953777

2) The consortium members where (academics); Erasmus University Rotterdam, Vrije Universiteit Amsterdam/IVM, Helsinki University of Technology, Triple

\section{Abbreviations}

$\begin{array}{ll}\text { 4Q } & \text { Four Quadrants Model (Wilber) } \\ \text { BE } & \text { Business Excellence } \\ \text { CS } & \text { Corporate Sustainability } \\ \text { CSR } & \text { Corporate Social Responsibility } \\ \text { CS-R } & \begin{array}{l}\text { Corporate Sustainability and Corporate } \\ \text { sponsibility }\end{array} \\ \text { ECSF } & \text { European Corporate Sustainability Framework } \\ \text { EFQM } & \text { European Foundation for Quality Management } \\ \text { EC } & \text { European Commission }\end{array}$

P Initiative; (Consultants): Virtu et Fortuna, SCS Consulting (Quality Organizations) KDI, European Organization for Quality, VCK, Excellence Ireland, Centre of Excellence Finland

3) For further reading, please read "a value based approach to ideal type organizations" in this edition, Spiral Dynamics (Beck and Cowan, 1996) and the website of the Spiral Dynamics Organization (NVC consulting and partners) at http://www.spiraldynamics.org.

4) See Van Marrewijk and Werre's article "Multiple Levels of Corporate Sustainability" in JoBE May 2003 on DBR's Value Audit (www.dbr.nl).

$\begin{array}{ll}\text { EU } & \text { European Union } \\ \text { GEM } & \text { Global Excellence Model } \\ \text { GPTW } & \text { Great Place to Work }{ }^{\circledR} \\ \text { HPO } & \text { High Performance Organizations } \\ \text { RSM } & \text { Rotterdam School of Management } \\ \text { RTI } & \text { Research to Improve } \\ \text { SDI } & \text { Spiral Dynamics Integral } \\ \text { TQM } & \text { Total Quality Management }\end{array}$

